\title{
PENGARUH PENDIDIKAN KESEHATAN TERHADAP TINGKAT PENGETAHUAN REMAJA TENTANG BAHAYA PERNIKAHAN DINI
}

\author{
The Effect Of Health Education On The Knowledge Level Of Youth About The Dangers \\ Of Early Marriage
}

\author{
Margaretha Eva Millenia \\ I* \\ Fitria Ningsih ${ }^{2}$ \\ Lensi Natalia Tambunan \\ 3
}

*I23STIKES Eka Harap Palangka

Raya, Palangka Raya,

Kalimantan Tengah, Indonesia

*email:

milleniaeva2000@gmail.com

\begin{abstract}
Abstrak
Latar Belakang : Pada era globalisasi saat ini, banyak permasalahan remaja yang terjadi sehingga mengakibatkan perilaku pernikahan dini terjadi seperti kurangnya pengetahuan remaja, keinginan diri sendiri akibat perasaan saling mencintai, keadaan sosial ekonomi rendah, pendidikan rendah, pergaulan bebas, kurangnya pengasuhan orang tua, dan pengaruh negatif media massa/informasi. Salah satu faktor yang mempengaruhi kejadian pernikahan dini adalah pengetahuan. Kurangnya pengetahuan tentang informasi dan pendidikan kesehatan seksual dan reproduksi pada remaja menyebabkan mereka tidak memiliki keterampilan dalam pengambilan keputusan yang tepat dan aman dari risiko seksual dan reproduksi sehingga memungkinkan melakukan hubungan seks pra nikah dan menyebabkan terjadinya pernikahan dini. Adapun faktor yang dapat mempengaruhi peningkatan pengetahuan adalah informasi yang diterima seperti pendidikan kesehatan.

Tujuan Penelitian : Penelitian ini bertujuan untuk mengetahui Pengaruh Pendidikan Kesehatan Terhadap Tingkat Pengetahuan Remaja Tentang Bahaya Pernikahan Dini berdasrkan data melalui metode literature review.

Hasil : Terdapat 6 jurnal yang menyatakan adanya pengaruh pendidikan kesehatan terhadap tingkat pengetahuan remaja tentang bahaya pernikahan dini hal ini ditunjukan dari hasil uji ekperimental setelah diberikan pendidikan kesehatan mengalami peningkatan pengetahuan yang signifikan.

Kesimpulan : Pemberian Pendidikan Kesehatan sangat mempengaruhi pengetahuan seseorang yang sebelumnya tidak tahu menjadi tahu, untuk itu edukasi tentang pernikahan dini harus terus diberikan kepada remaja agar terhindar dari dampak negatif pernikahan dini.

Daftar Pustaka : 45 (20II-2020)
\end{abstract}

Kata Kunci:

Pendidikan Kesehatan

Pengetahuan

Pernikahan Dini

Keywords:

Health Education

Knowledge

Early Marriage

\section{Abstract}

Background: In the current era of globalization, many adolescent problems occur resulting in early marriage behavior such as lack of adolescent knowledge, self-desire due to feelings of love, low socioeconomic circumstances, low education, free association, lack of parental care, and negative influence of mass medial information. One of the factors that influence the incidence of early marriage is knowledge. A lack of knowledge about sexual and reproductive health information and education in adolescents causes them to lack the skills to make informed and safe decisions about sexual and reproductive risks, thus enabling premarital sex and leading to early marriage. The factors that can influence the increase in knowledge are information received such as health education.

Research Objectives: This study aims to determine the effect of health education on the level of knowledge of adolescents about the dangers of early marriage based on data through the literature review method.

Research Methods: Using the literature review method. Search journals using an academic database, namely Google Scholar which was published in 2017-202I using Indonesian and English. Research design Eksperimental.

Results: There are 6 journals that state the influence of health education on the level of knowledge of adolescents about the dangers of early marriage is shown from the results of ecperimental tests after being given health education experienced a significant increase in knowledge.

Conclusion: The provision of Health Education greatly affects the knowledge of someone who previously did not know to know, therefore education about early marriage should continue to be given to adolescents in order to avoid the negative impact of early marriage.

Bibliography : 45 (201 I-202I) 


\section{PENDAHULUAN}

Remaja adalah masa peralihan dari masa kanak-kanak menuju dewasa. Di dalam masa ini proses pertumbuhan dan perkembangan terjadi sangat cepat, baik dari segi fisik, maupun psikologis, pada masa ini perkembangan emosi masih belum stabil. Pada era globalisasi saat ini, banyak permasalahan yang terjadi seperti kurangnya pengetahuan remaja terhadap dampak yang akan ditimbulkan jika melakukan pernikahan dini, keinginan diri sendiri akibat perasaan saling mencintai, keadaan sosial ekonomi rendah, pendidikan rendah, pergaulan bebas, kurangnya pengasuhan orang tua, dan pengaruh negatif media massa/informasi. Pernikahan dini didefinisikan sebagai pernikahan yang terjadi sebelum anak mencapai usia 19 tahun, sebelum anak matang secara fisik, fisiologis, dan psikologis untuk bertanggungjawab terhadap pernikahan dan anak yang dihasilkan dari pernikahan tersebut. Karena kurangnya paparan informasi dan pengetahuan remaja yang didapatkan terhadap dampak pernikahan dini akibatnya perilaku pernikahan dini terjadi. Salah satu faktor yang dapat mempengaruhi pengetahuan dan perubahan perilaku adalah pendidikan kesehatan. Peningkatan pengetahuan melalui pendidikan kesehatan memiliki kontribusi yang kuat dalam pengambilan sikap dan keputusan yang akan diambil semakin tinggi pengetahuan seseorang maka pernikahan dini dapat dicegah dan diminimalisir (Kesehatan et al., 202I).

Berdasarkan Survei Demografi Kesehatan (SDKI) yang dilakukan oleh BKKBN Kalteng pada tahun 2017 rentang usia 15-19 tahun ditemukan sebanyak 89 kasus, namun terjadi penurunan pada tahun 2018 menjadi 83 kasus. Akan tetapi dalam SDKI Nasional, Kalimantan Tengah masih menempati angka tertinggi kasus pernikahan dini yaitu masuk urutan ketiga setelah Jawa Barat dan Kalimantan Barat. Data dari Pengadilan Agama Kota Palangkaraya pada tahun 2019 terdapat 20 permohonan dispensasi menikah dibawah usia 19 tahun, namun pada tahun 2020 yakni pada periode Januari-Oktober melonjak 3 kali lipat yaitu terdapat 57 permohonan dan kasus ini terus bertambah selama masa pandemi covid-19. Pada data Dinas Pemberdayaan Perempuan Perlindungan Anak Pengendalian Penduduk dan Keluarga Berencana pada tahun 2021 Kalteng telah menempati urutan kedua secara nasional dengan kasus pernikahan tertinggi di Indonesia.

Banyak faktor yang mempengaruhi kejadian pernikahan dini diantaranya adalah faktor pengetahuan. Adapun faktor yang mempengaruhi pengetahuan adalah informasi yang diterima seperti pendidikan kesehatan. Pendidikan Kesehatan merupakan proses yang menjembatani kesenjangan antara informasi kesehatan dan praktek kesehatan, yang memotivasi seseorang untuk memperoleh informasi dan menjaga dirinya menjadi lebih sehat dengan menghindari kebiasaan buruk dan membentuk kebiasaan yang menguntungkan kesehatan. Tujuan pendidikan kesehatan adalah mengubah perilaku dari yang merugikan kesehatan atau tidak sesuai dengan norma kesehatan ke arah tingkah laku yang menguntungkan kesehatan atau norma yang sesuai dengan kesehatan. Maka dari itu melalui pemberian pendidikan kesehatan akan meningkatkan pengetahuan remaja tentang pernikahan dini. Berdasarkan hasil penelitian, pengetahuan memiliki kontribusi yang kuat dalam pengambilan sikap atau keputusan yang akan diambil sesorang. Maka dari itu, pentingnya pemberian pendidikan kesehatan reproduksi dan kesehatan seksual remaja baik secara formal maupun non formal seperti yang dikemukakan oleh Suryoputro \& Widjanarko (2016) penting diadakannya suatu program pendidikan yang tepat dan komprehensif mengenai kesehatan seksual dan reproduksi yang dapat diperkenalkan melalui sekolahsekolah, dan menurut Minguez (2015) dan Arisjulyanto, Ismail, \& Fuad (2019) pemberian pendidikan kesehatan merupakan salah satu upaya yang tepat dalam mengatasi bahaya pernikahan dini dan masalah-masalah kesehatan reproduksi remaja 
(Rosamali \& Arisjulyanto, 2020). Adapun solusi yang dapat diberikan sebagai tenaga kesehatan masyarakat adalah dengan pemberian pendidikan kesehatan kepada remaja dan orang tua terkait dampak dari pernikahan dini.

Berdasarkan uraian di atas maka peneliti tertarik meneliti judul Pengaruh Pendidikan Kesehatan Terhadap Tingkat Pengetahuan Remaja Tentang Bahaya Pernikahan Dini.

\section{METODOLOGI}

Metode Penelitian yang digunakan dalam penelitian ini adalah literatur review. literatur review adalah analisis terintegrasi tulisan ilmiah yang terkait langsung dengan pertanyaan penelitian (Nursalam, 2017).

Pada penelitian literatur review ini judul yang akan diteliti adalah Pengaruh Pendidikan Kesehatan Terhadap Tingkat Pengetahuan Remaja Tentang Bahaya Pernikahan Dini.

\section{HASIL DAN PEMBAHASAN}

Hasil dari pencarian litrature telah ditentukan 6 jurnal yang terkait dengan pengaruh pendidikan kesehatan terhadap tingkat pengetahuan remaja tentang bahaya pernikahan dini pada remaja. Berdasarkan 6 jurnal tersebut terdapat 6 jurnal yang menyatakan terdapat pengaruh pendidikan kesehatan terhadap tingkat pengetahuan remaja tentang bahaya pernikahan dini. Hal ini sesuai dengan penelitian Rosamali.dkk (2020) menyatakan bahwa studi pendahuluan dengan menggunakan teknik wawancara, dengan jumlah sampel 30 orang remaja menunjukan bahwa masih kurangnya pengetahuan remaja tentang bahaya pernikahan dini, 9 orang remaja berpengetahuan cukup dan 21 orang remaja berpengetahuan kurang. Berdasarkan hasil uji statistik, penelitian ini menunjukan ada perbedaan tingkat pengetahuan remaja tentang bahaya pernikahan dini sebelum dan sesudah diberikan pendidikan kesehatan, dan mengalami peningkatan pengetahuan setelah diberikan pendidikan kesehatan, yang berarti ada pengaruh pendidikan kesehatan terhadap tingkat pengetahuan remaja tentang bahaya pernikahan dini.

Selain itu penelitian Amelia Mohdari. dkk (2017) menyatakan bahwa diketahui 15 orang (19,2\%) yang berpengetahuan kurang, sebanyak 44 orang $(56,4 \%)$ berpengetahuan cukup dan sebanyak 19 orang (24,4\%) berpengatahuan baik setelah diberikan penyuluhan. Hasil penelitian terhadap pengetahuan sebelum dilakukan penyuluhan responden yang didapat yaitu 18 orang $(23,1 \%)$ responden menunjukkan pengetahuan kurang dan sesudah dilakukan penyuluhan terdapat pengaruh yang signifikan yaitu terdapat 15 orang $(14,2 \%)$ responden menunjukkan pengetahuan kurang, sedangkan untuk pengetahuan perbedaan yang signifikan sebelum dan sesudah dilakukan penyuluhan dimana untuk pengetahuan yang baik sebelum dilakukan penyuluhan 4 orang $(5,1 \%)$ terdapat peningkatan yang signifikan sesudah dilakukan penyuluhan menjadi 19 orang (24,4\%). Berdasarkan hasil penelitian sebelum dan sesudah dilakukannya pendidikan kesehatan menunjukan adanya perbedaan dimana terjadi peningkatan pengetahuan remaja tentang bahaya pernikahan dini. Dengan demikian berarti ada pengaruh pendidikan kesehatan terhadap tingkat pengetahuan remaja tentang bahaya pernikahan dini.

Prahesti (2018) menyatakan bahwa 33 responden setelah diberikan pendidikan kesehatan sebagian besar mengalami peningkatan pengetahuan yaitu sebanyak 21 responden $(63,6 \%)$ pengetahuan tetap sebanyak 7 responden $(21,2 \%)$, pengetahuan kurang sebanyak 5 responden (I5,I\%). Hal ini menunjukkan adanya perbedaan peningkatan penegatahuan sebelum dan sesudah diberikan pendidikan kesehatan. Berdasarkan hasil kuesioner pretest dan postest peneliti menemukan adanya pengaruh penyuluhan kesehatan reproduksi terhadap pengetahuan remaja tentang pernikahan dini pada siswa kelas X SMA N I Banguntapan. 
Penelitian Kesehatan et al., (202I) menyatakan bahwa terjadi peningkatan rata-rata skor pengetahuan responden setelah diberikan pendidikan kesehatan dari 60 responden terdapat 8 responden yang memiliki pengetahuan menurun, 4 responden pengetahuan tetap dan 48 responden mengalami peningkatan pengetahuan setelah diberikan pendidikan kesehatan. Berdasarkan hasil penelitian tersebut dapat disimpulkan bahwa ada pengaruh pemberian pendidikan kesehatan terhadap peningkatan pengetahuan remaja puteri di Desa Waiheru. Peningkatan pengetahuan remaja putri tentang pernikahan dini setelah diberikan pendidikan kesehatan dalam bentuk penyuluhan dan pembagian leaflet sangat terlihat signifikan, hal ini dapat terbukti dengan adanya peningkatan pengetahuan remaja pada saat post test.

(Studi et al., 2018) menyatakan bahwa dari sample 33 responden, responden dengan pengetahuan baik sebanyak 17 responden $(5 \mathrm{I}, \mathrm{I} \%)$, responden dengan pengetahuan cukup sebanyak 16 responden (48,5\%) dan responden dengan pengetahuan kurang tidak ada. Berdasrkan hasil uji dapat diketahui bahwa terdapat peningkatan pengetahuan sebelum dan sesudah diberikan pendidikan kesehatan. Hal tersebut menandakan bahwa ada pengaruh sebelum diberikan penyuluhan dengan setelah diberikan penyuluhan terhadap tingkat pengetahuan responden.

Selain itu penelitian Maya et al., (2019) juga menyatakan berdasarkan peserta penyuluhan yang hadir sebanyak 30 siswi yang duduk di kelas XI IPS 2 SMA Negeri 14 Palembang terdapat pengaruh peningkatan pengetahuan. Peningkatan pengetahuan peserta dapat diketahui melalui perbandingan hasil pretest dan posttest yang diajukan secara lisan sebelum dan sesudah dilakukannya pendidikan kesehatan. Sebelum dilakukannya pendidikan kesehatan para siswa menjawab pertanyaan yang diajukan dengan jawaban yang masih umum dan terbatas, setelah mengikuti pendidikan kesehatan siswa dapat menjawab pertanyaan dengan lancar dan detail.

\section{KESIMPULAN}

Berdasarkan hasil telaah dari 6 artikel penelitian yang dilakukan oleh peneliti mengenai Pengaruh Pendidikan Kesehatan Terhadap Tingkat Pengetahuan Remaja Tentang Bahaya Pernikahan Dini maka penulis simpulkan bahwa :

Terdapat 6 jurnal yaitu Rosamali. dkk (2020), Amelia Mohdari. dkk (2017), Prahesti (2018), Kesehatan et al., (202I), Studi et al., (2018), dan Maya et al., (2019) menyatakan adanya peningkatan pengetahuan remaja setelah diberikan pendidikan kesehatan tentang bahaya pernikahan dini. Maka dari itu melalui hasil penelitian ini, upaya pemberian informasi melalui pendidikan kesehatan sangat berpengaruh dalam peningkatan pengetahuan responden mengenai pernikahan dini serta dapat dilakukan melalui pembentukan pusat informasi dan konseling bagi remaja di sekolah yang para konselornya adalah dari para remaja yang di ikutkan pelatihan dan telah mendapat pengetahuan tentang pernikahan dini dan juga pihak sekolah bisa menjalin kerjasama dengan pihak tenaga kesehatan sehingga responden dapat lebih mengantisipasi dirinya terhadap perilaku yang berisiko baik dengan cara pemberian penyuluhan ataupun seminar tentang kesehatan reproduksi dari sumber yang benar.

\section{UCAPAN TERIMA KASIH}

Puji syukur peneliti panjatkan kepada Tuhan Yang Maha Esa, karena atas berkat dan rahmat-Nya, peneliti dapat menyelesaikan penyusunan Skripsi ini. Penulisan Skripsi ini dilakukan dalam rangka memenuhi salah satu syarat untuk mencapai gelar Sarjana Kesehatan Masyarakat pada Sekolah Tinggi Ilmu Kesehatan Palangka Raya. Peneliti menyadari bahwa, tanpa bantuan dan bimbingan dari berbagai pihak pada penyusunan Skripsi ini, sangatlah sulit bagi peneliti untuk menyelesaikan 
laporan ini. Oleh karena itu peneliti mengucapkan terima kasih kepada:

I) Maria Adelheid Ensia, S.Pd., M.Kes selaku Ketua STIKes Eka Harap Palangka Raya.

2) Fitriani Ningsih, SST., M.Kes selaku dosen pembimbing I yang telah menyediakan waktu, tenaga, dan pikiran untuk mengarahkan peneliti dalam penyusunan Skripsi ini.

3) Lensi Natalia Tambunan SST., M.Kes selaku dosen pembimbing II yang telah menyediakan waktu, tenaga, dan pikiran untuk mengarahkan peneliti dalam penyusunan Skripsi ini.

4) Rizki Muji Lestari, SST., M.Kes selaku Ketua Penguji.

5) Orang tua dan keluarga peneliti yang telah memberikan bantuan dukungan material dan moral.

6) Sahabat yang telah banyak membantu dalam menyelesaikan skripsi ini.

Semoga bantuan serta budi baik yang telah diberikan kepada peneliti, mendapat balasan dari Tuhan Yang Maha Esa. Besar harapan peneliti agar Skripsi ini dapat bermanfaat.

\section{REFERENSI}

I. Kesehatan, P., Baguala, K., \& Ambon, K. (202I). DOI: $\quad h t t p: / / d x . d o i . o r g / / 0.33846 / s f I 2 n k / 32$ Peningkatan Pengetahuan dan Sikap Remaja Putri tentang Dampak Pernikahan Dini melalui Pemberian Pendidikan Kesehatan di Desa Waiheru, Kecamatan Baguala Kota Ambon Dewi Arwini Bugis. 12(2), I73177.

2. Kementerian Kesehatan Republik Indonesia. (20I4). Riset Kesehatan Dasar. Kementerian Kesehatan RI.

3. BKKBN. (20I7). Bkkbn: Usia Pernikahan Ideal 2I25 Tahun. E-Journal. https://www.bkkbn.go.id/detailpost/bkkbn-usiapernikahan-ideal-2I-25-tahun

4. Suryoputro, A. (2017). Perilaku Seksual Remaja di Lingkungan Lokalisasi Kabupaten Sidoarjo.
5. Arisjulyanto, D. (2019). Intensity Of Social Media Use With Premarital Sexual Behaviour Of Adolescents In SMK 2 Gerug West Lombok. Universitas Gadjah Mada.

6. Rosamali, A., \& Arisjulyanto, D. (2020). Pengaruh Pendidikan Kesehatan Terhadap Tingkat Pengetahuan Remaja Tentang Bahaya Pernikahan Dini Di Lombok Barat. JISIP (Jurnal IImu Sosial Dan Pendidikan), $4(3)$. https://doi.org/10.36312/jisip.v4i3.1 |43

7. Nursalam. (2017). Metodologi Penelitian IImu Keperawatan: Pendekatan Praktis. Cet. 2. Salemba Medika.

8. Amelia Mohdari; Azizah, Aulia, R. M. (2017a). Pengaruh Penyuluhan Terhadap Pengetahuan Remaja Tentang Pernikahan Dini Di Kelas Viii Di Smp Negeri 4 Banjarmasin. Dinamika Kesehatan Jurnal Kebidanan Dan Keperawatan, 8(Vol 8, No I (2017):Dinamika Kesehatan Jurnal Kebidanana dan Keperawatan), 5/10/2020 jam 09.20. http://ojs.dinamikakesehatan.stikessarimulia.ac.id/in dex.php/dksm/article/view/230

9. Amelia Mohdari; Azizah, Aulia, R. M. (2017b). Pengaruh Penyuluhan Terhadap Pengetahuan Remaja Tentang Pernikahan Dini Di Kelas Viii Di Smp Negeri 4 Banjarmasin. Dinamika Kesehatan Jurnal Kebidanan Dan Keperawatan, 8(Vol 8, No I (2017):Dinamika Kesehatan Jurnal Kebidanana dan Keperawatan).

10. Prahesti, E. (2018). Pengaruh Penyuluhan Kesehatan Reproduksi Terhadap Pengetahuan Pernikahan Dini Pada Siswa Kelas X Di Sman I Banguntapan Bantul. http://digilib.unisayogya.ac.id/4002/

II. BKKBN. (20I2). Pernikahan dini pada beberapa provinsi di Indonesia: akar masalah dan peran kelembagaan di daerah. BKKBN Nasional.

12. Studi, P., Program, K., Terapan, S., \& Kesehatan, F. I. (2018). Pengaruh Penyuluhan Tentang Early Marriage.

13. Maya, R. A. A., Andriani, R., \& Priyanti, E. (20/9). Pendidikan Kesehatan Tentang Dampak Pernikahan Dini Terhadap Kehamilan Remaja Di Sma Negeri 14 Palembang. Khidmah, 2(I). 